\title{
A Photo-Enzymatic Cascade to Transform Racemic Alcohols into Enantiomerically Pure Amines
}

\author{
Jenő Gacs ${ }^{1}$, Wuyuan Zhang ${ }^{1}$, Tanja Knaus ${ }^{2}$, Francesco G. Mutti ${ }^{2}{ }^{\circledR}$, Isabel W.C.E. Arends ${ }^{1}$ and \\ Frank Hollmann 1,*(D) \\ 1 Department of Biotechnology, Delft University of Technology, Van der Maasweg 9, 2629HZ Delft, \\ The Netherlands; gacsjeno@gmail.com or acsjeno@gmail.com (J.G.); w.zhang-1@tudelft.nl (W.Z.); \\ I.W.C.E.Arends@uu.nl (I.W.C.E.A.) \\ 2 Van't Hoff Institute for Molecular Sciences (HIMS-Biocat), University of Amsterdam, Science Park 904, \\ 1098 XH Amsterdam, The Netherlands; T.Knaus@uva.nl (T.K.); F.Mutti@uva.nl (F.G.M.) \\ * Correspondence: f.hollmann@tudelft.nl; Tel.: +31-(0)152-781957
}

Received: 27 February 2019; Accepted: 20 March 2019; Published: 27 March 2019

check for updates

\begin{abstract}
The consecutive photooxidation and reductive amination of various alcohols in a cascade reaction were realized by the combination of a photocatalyst and several enzymes. Whereas the photocatalyst (sodium anthraquinone-2-sulfonate) mediated the light-driven, aerobic oxidation of primary and secondary alcohols, the enzymes (various $\omega$-transaminases) catalyzed the enantio-specific reductive amination of the intermediate aldehydes and ketones. The system worked in a one-pot one-step fashion, whereas the productivity was significantly improved by switching to a one-pot two-step procedure. A wide range of aliphatic and aromatic compounds was transformed into the enantiomerically pure corresponding amines via the photo-enzymatic cascade.
\end{abstract}

Keywords: photooxidation; cascade; alcohol; reductive amination; $\omega$-transaminase

\section{Introduction}

In recent years, significant attention has been devoted to the synthesis of amines [1]. Especially, enantiomerically pure amines are of interest in natural product synthesis, as intermediates in pharmaceutical synthesis, and for a variety of other chemical products [2-4]. Direct amination of alcohols has been studied extensively [1,5]. The main advantage of prompt conversion of alcohols to amines is that both the substrate and the product are in the same oxidation state, and, thus, theoretically the additional use of any redox equivalents is not required [6,7]. Furthermore, many of the required alcohols are already available on an industrial scale, which facilitates the mass application of the technology [8]. On the other hand, most of the currently applied reactions either possess poor chemo-selectivity and require harsh reaction conditions (e.g., the reaction of alcohol with ammonia over various heterogeneous catalysts, such as tungsten, cobalt, nickel, chromium) [5] or have low efficiency and produce toxic intermediates [9]. It is also worth mentioning that the majority of the current methodologies either only accept symmetric substrates or produce racemic products. To synthesize chiral amine moieties, ketones are one of the most commonly used precursors [1].

Various approaches have been reported to selectively oxidize alcohols to the corresponding carbonyl products [10-13]. Compared to transition metal-based approaches [14], photooxidation provides an atom-economic and environmentally benign alternative [10]. Commercially available $\mathrm{TiO}_{2}$ is used most commonly as a photocatalyst, but the applicability is restricted by its UV absorption [15]. However, efficient oxidation of 1-pentanol has been reported by irradiation up to $480 \mathrm{~nm}$ upon doping $\mathrm{TiO}_{2}$ with $\mathrm{Nb}_{2} \mathrm{O}_{5}[16,17]$. To further utilize visible light, numerous other heterogeneous catalysts have been tested [18]. By using graphitic carbon nitride $\left(g-C_{3} N_{4}\right)[19,20]$ and vanadium-oxide grafted 
to numerous carriers [21,22], efficient alcohol oxidation mediated by visible light has been reported. Besides heterogeneous systems, water-soluble sodium anthraquinone-2-sulfonate (SAS) is also known as an effective and inexpensive homogeneous photocatalyst [23-27]. Very recently we found that SAS is also very active for the oxidation of $\mathrm{C}-\mathrm{H}$ bonds [27] and, therefore, can be implemented in photo-enzymatic cascades for the conversion of a very large substrate scope [28].

Even though photocatalysis provides an attractive approach to produce the carbonyl intermediate, typically, tedious protection/de-protection steps are required for the synthesis of chiral amines. These additional stages prolong the synthesis time and significantly decrease the atom efficiency of the reaction. To aid these shortcomings, biocatalytic approaches have been extensively studied [29-32]. Pyridoxal-5-phosphate (PLP)-dependent $\omega$-transaminases ( $\omega$-TAs) provide an elegant way to convert a carbonyl group to an amine moiety at the expense of a sacrificial amine donor $[31,33]$. $\omega$-TAs have been increasingly applied in industrial chemical synthesis, in particular for the manufacturing of active pharmaceutical ingredients (APIs) [29,34,35]. Other main applications deal with the production of surfactants [36], amino acids [37], and plastic fiber monomers [36,38,39]. To reach an acceptable conversion when L- or D-alanine is used as an amine donor, the reaction equilibrium of the transamination reaction must be shifted towards the product. Thus, one of the most common means to enhance the amine formation is to remove the pyruvate by-product through the addition of another enzyme, such as lactate dehydrogenase (LDH), alanine dehydrogenase (AlaDH), pyruvate decarboxylase (PDC), or an acetolactate synthase (ALS) [32]. On the other hand, the use of alternative amine donors provides a more favorable thermodynamic equilibrium. However, these molecules are either prohibitively expensive [39] or generate a co-product during the transamination that tends to polymerize, thus complicating product isolation and lowering product yield [40,41]. Therefore, it is not surprising that isopropylamine (IPA) has been used as the preferred amine donor, especially on an industrial scale. IPA is inexpensive and provides a much more favorable thermodynamic equilibrium compared to alanine [42], which can be further shifted via simple and selective evaporation of the low boiling acetone co-product [35]. Consequently, IPA was selected as the amine donor in this study.

Recently, numerous reports have been published about the effective conversion of a plethora of alcohols to (chiral) amines in multi-enzyme cascades $[43,44]$. Inspired by their results and the current advances in the selective photochemical oxidation of alcohols [18], herein we present a photo-enzymatic tandem reaction for the direct conversion of alcohols to (chiral) amines. Employing the consecutive oxidation and reductive amination steps in one pot, a further reduction of the environmental impact of the synthesis is possible (Scheme 1). As time-consuming intermediate isolation and purification steps are omitted, the required amount of organic solvents is minimized, which results in a lower E-factor (Environmental factor, defined as the mass of waste per mass of product) $[45,46]$.

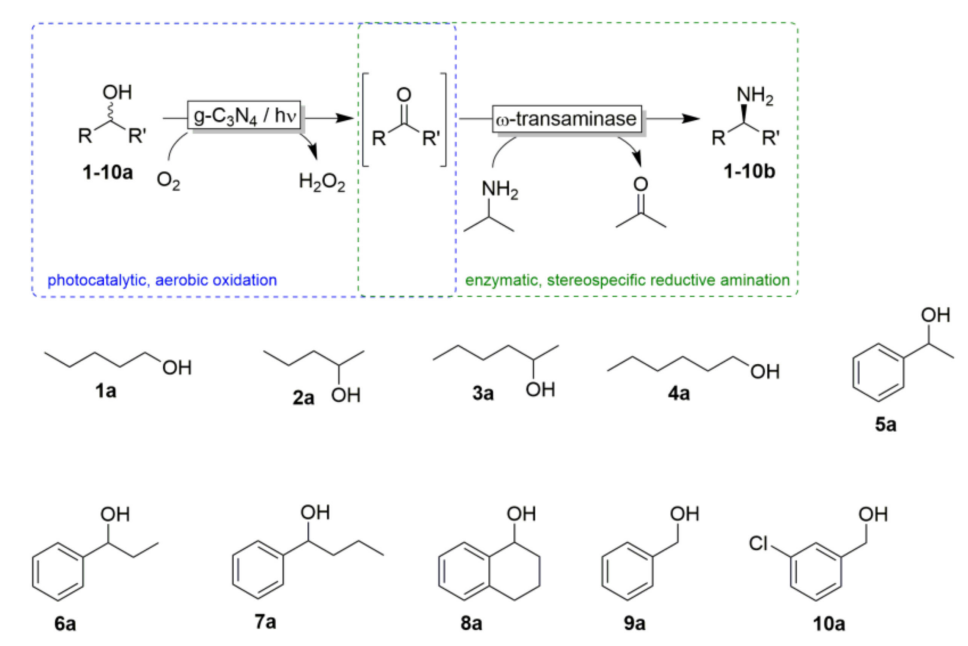

Scheme 1. Schematic representation of the photo-enzymatic cascade reaction and the examined substrates. 


\section{Results and Discussion}

In the first set of experiments, we evaluated a range of homogeneous and heterogeneous photocatalysts available in our laboratory. More specifically, water-soluble sodium anthraquinone-2-sulfonate (SAS) and heterogeneous graphitic carbon nitride $\left(\mathrm{g}^{-} \mathrm{C}_{3} \mathrm{~N}_{4}\right)$, niobium $(\mathrm{V})$-oxide-doped titanium-dioxide $\left(\mathrm{TiO}_{2}-\mathrm{Nb}_{2} \mathrm{O}_{5}\right)$, and vanadium oxide $(\mathrm{VO})$ deposited on various carriers, such as alumina $\left(\mathrm{VO}-\mathrm{Al}_{2} \mathrm{O}_{3}\right)$, zirconium-dioxide $\left(\mathrm{VO}-\mathrm{ZrO}_{2}\right)$, and graphitic carbon nitride (VO-g- $\mathrm{C}_{3} \mathrm{~N}_{4}$ ), were evaluated. As a model reaction, we chose the oxidation of rac-1-phenylethanol (5a) to acetophenone (5b) (Figure 1). Starting from $25 \mathrm{mM}$ of the starting material, SAS mediated the full conversion of $5 \mathbf{a}(\mathrm{TN}=30)$, while the best heterogeneous catalyst, $\mathrm{g}-\mathrm{C}_{3} \mathrm{~N}_{4}$, produced only $6.2 \mathrm{mM}$ of product with $20 \%$ conversion. The discrepancy between conversion and product concentration in the case of SAS is probably due to the oxidative decomposition of the product. Since the other photocatalysts fell back significantly in their performance (Figure 1), we focused our attention on SAS and $\mathrm{g}-\mathrm{C}_{3} \mathrm{~N}_{4}$.

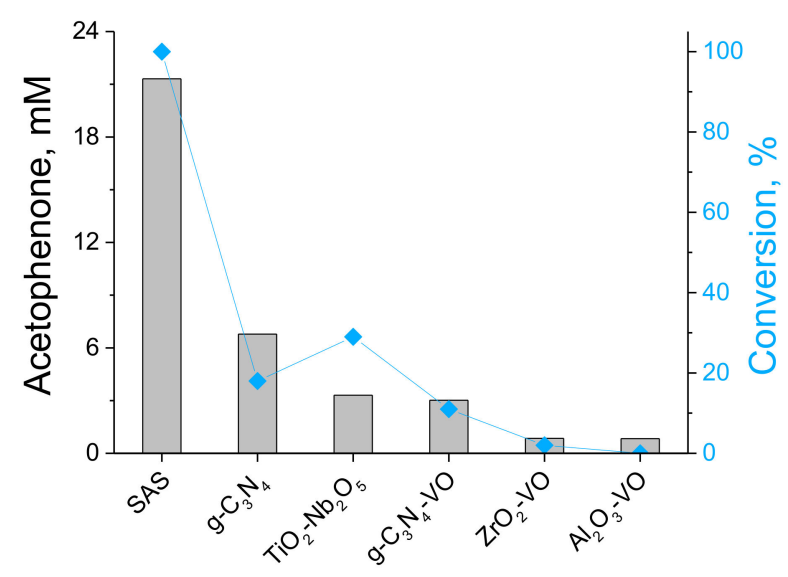

Figure 1. Alcohol oxidation using various photocatalysts. Reaction conditions: $1 \mathrm{~mL}$ MilliQ water with [5a] = $25 \mathrm{mM}$, [sodium anthraquinone-2-sulfonate (SAS)] $=0.75 \mathrm{mM}$, or [heterogeneous photocatalyst] $=10 \mathrm{mg} / \mathrm{mL}$. Reactions were performed for $24 \mathrm{~h}$ at $30^{\circ} \mathrm{C}$ under atmospheric conditions and irradiated under visible light $(\lambda>400 \mathrm{~nm})$. These experiments have been performed as single experiments.

We performed the cascade reaction shown in Scheme 1 using SAS and $g-\mathrm{C}_{3} \mathrm{~N}_{4}$ in a one-pot one-step fashion, i.e., adding the starting material and all catalysts at the beginning (Figure 2). For the reductive amination of the intermediate ketone, two $\omega$-transaminases were applied: the $(R)$-selective

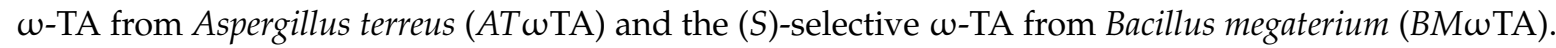
In the case of $\mathrm{g}-\mathrm{C}_{3} \mathrm{~N}_{4}$, virtually no alcohol conversion was observed. The trace amounts of rac-5c originated from small acetophenone impurities within the commercial substrate. We attribute this lack of catalytic activity to the absorption of the biocatalysts to the $\mathrm{g}-\mathrm{C}_{3} \mathrm{~N}_{4}$ surface, thereby passivating it for the desired oxidation reaction.

The cascade reaction using SAS, however, produced $2.5 \mathrm{mM}(S)$ - and $1.5 \mathrm{mM}(R)$-1-phenylethyl amine in $48 \mathrm{~h}$. Even though enantiomerically pure amines were obtained, the performance of this system fell back behind our expectations. Therefore, we set out to investigate the limitations of the one-pot one-step procedure. Further characterization of the reaction conditions revealed some limitations of the one-pot one-step procedure to be as follows: (i) the catalytic activity decreased steadily in the presence of light and SAS. This may be attributed to an oxidative inactivation and degradation of the biocatalysts by photoexcited SAS and the used light (Figure S9); (ii) we found that the rate of the first step (SAS-mediated oxidation of phenylethanol) was significantly slower in the case of the one-pot one-step procedure. This may be attributed to SAS's activity on the stoichiometric amine donor and the product of the reductive amination step (Figures S11-S13). 
A

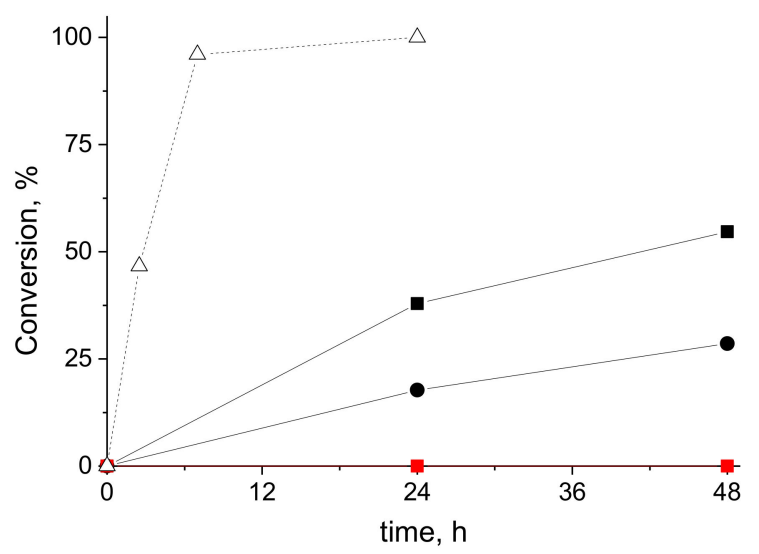

B

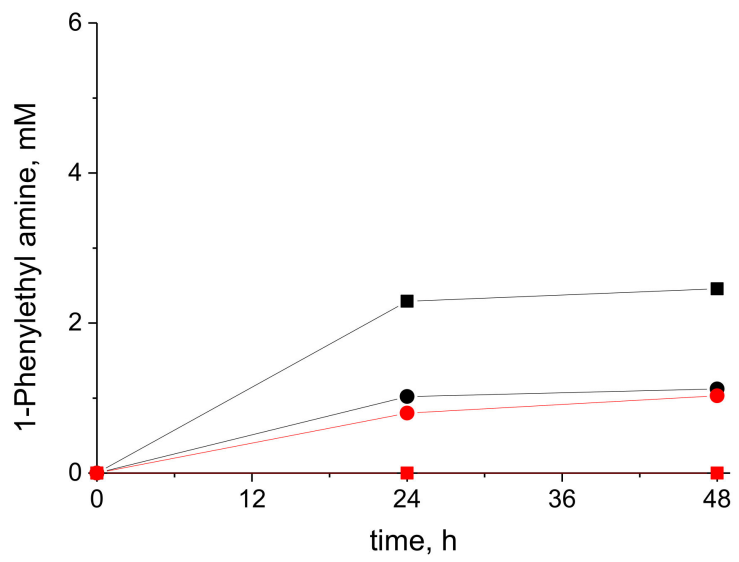

Figure 2. Results of the direct amination of 1-phenylethanol (5a) in a one-pot one-step fashion with SAS

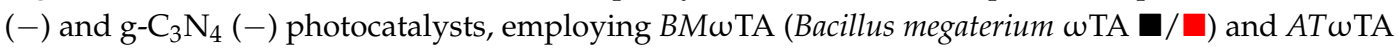
(Aspergillus terreus $\omega \mathrm{TA} \bullet / \bullet$ ) enzymes. (A) Conversion of $5 \mathbf{a}$. As a comparison, the conversion of $20 \mathrm{mM}$ 5a in MilliQ water containing 0.75 mM SAS is also shown $(\triangle)$; (B) Production of 1-phenylethyl amine 5c. Reaction conditions: $1 \mathrm{~mL}$ reaction mixture containing sodium phosphate $(\mathrm{NaPi})$ buffer $(100 \mathrm{mM}, \mathrm{pH} 9)$, [1-phenylethanol] $=15 \mathrm{mM},[S A S]=0.75 \mathrm{mM}$, [isopropylamine, IPA] $=1 \mathrm{M},[$ Pyridoxal-5-phosphate, $\mathrm{PLP}$ ] $=1 \mathrm{mM}$, [crude cell extract overexpressed with $\omega$-TA enzyme] $=10 \mathrm{mg} / \mathrm{mL}$. Reaction mixtures were incubated at $30^{\circ} \mathrm{C}$, irradiated with white light $(\lambda>400 \mathrm{~nm})$.

Therefore, we turned our attention to a one-pot two-step procedure, wherein we first performed the photochemical alcohol oxidation followed by supplementation of the reaction mixture containing the reaction components needed for the reductive amination in a second step. Compared to the one-pot one-step case, the rate of the oxidation increased meaningfully, and the amount of product $5 \mathrm{c}$ doubled with excellent enantiomeric excess (>99\%) (Figure 3).

A

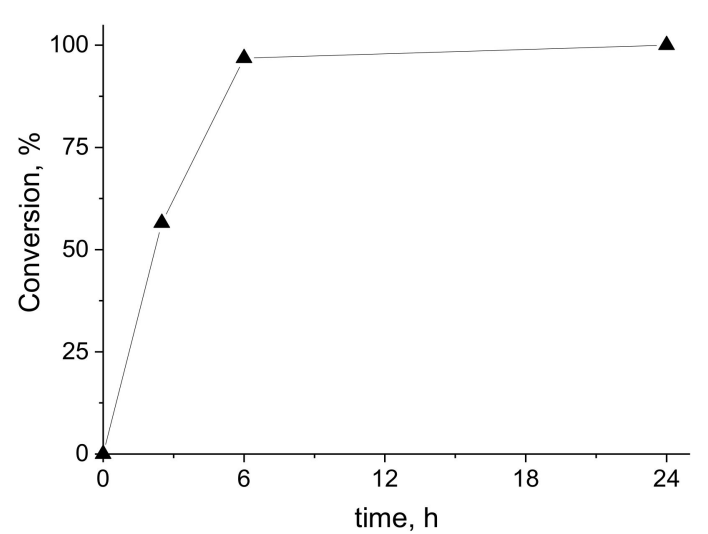

B

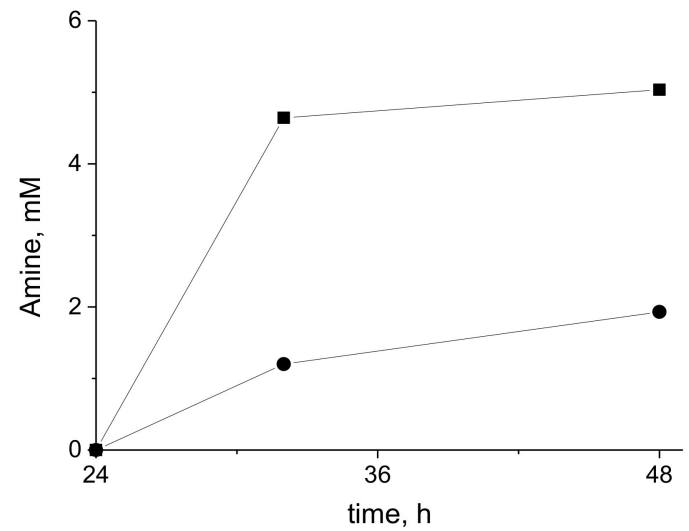

Figure 3. Results of the direct amination of 1-phenylethanol (5a) in a one-pot two-step fashion. (A)

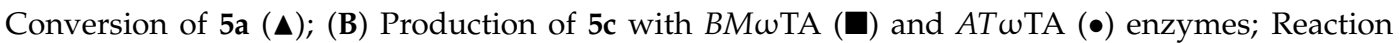
conditions: (A) $1 \mathrm{~mL}$ MilliQ water containing [5a] $=10 \mathrm{mM}$, [SAS] $=0.75 \mathrm{mM}$. Samples were incubated at $30{ }^{\circ} \mathrm{C}$ and irradiated under visible light $(\lambda>400 \mathrm{~nm}) ;(B) 0.5 \mathrm{~mL} \mathrm{pH} 9$ reaction mixture containing $[\mathrm{NaPI}]=50 \mathrm{mM},[\mathrm{IPA}]=1 \mathrm{M},[\mathrm{PLP}]=1 \mathrm{mM}$, [crude cell extract overexpressed with $\omega$-TA enzyme $]=$ $10 \mathrm{mg} / \mathrm{mL}$. Samples were incubated on a shaking plate at $30^{\circ} \mathrm{C}$ at $600 \mathrm{rpm}$.

To gain more insight into the performance of the $\omega$-transaminases, we varied the enzyme, amine donor, and cofactor concentrations. An increase in the enzyme concentration resulted in a higher initial reaction rate. However, approx. $2.9 \mathrm{mM}$ of product was formed for all cases after $28 \mathrm{~h}$ using $1 \mathrm{M}$ of IPA at $\mathrm{pH} 9$ (Figure S23). Using the same concentration of IPA but increasing the $\mathrm{pH}$ to 10.2 
led to a progressive increase in the yield above $6 \mathrm{mM}$ (Figure S26). These data are in agreement with previous publications, which indicate that the deprotonated form of IPA in aqueous solution might act as the actual amine donor $[35,47,48]$. Testing different concentrations of IPA at $\mathrm{pH} 9(0.5,1,2 \mathrm{M})$ resulted in both higher initial rate and final product concentration (Figure S24), as also the amount of free IPA amino donor in solution increased accordingly. We concluded that the final obtained conversion was determined by the actual concentration of free IPA in solution and the thermodynamic equilibrium constant of the reaction [42], and not by the stability of the biocatalyst. Therefore, the productivity of our system can be increased in the future by process engineering aimed at the selective removal of the acetone co-product. Finally, varying the concentration of the cofactor PLP did not show any noticeable influence on the product formation (Figure S25), which is also in agreement with previous findings. Conversely, an excessively high concentration of PLP is not only inconvenient economically but can also inhibit the $\omega$-TA [49]. Based on the above findings, we chose the following parameters for our next investigation: [with $\omega$-TA enzyme] $=10 \mathrm{mg} / \mathrm{mL},[\mathrm{IPA}]=1 \mathrm{M}$, and [PLP] = $1 \mathrm{mM}$. The reactions were performed at $30^{\circ} \mathrm{C}$, an optimal temperature for both the photooxidation and reductive amination steps.

To further explore the scope of the one-pot two-step procedure, we investigated a broader scope of starting materials including aliphatic, aromatic, chiral, and non-chiral substrates (Scheme 1 and Table 1).

Table 1. Photocatalytic oxidation of various alcohols.

\begin{tabular}{ccc}
\hline Substrate & Conversion $^{\mathbf{a}} \mathbf{( \% )}$ & Yield $^{\mathbf{b}} \mathbf{( \% )}$ \\
\hline $\mathbf{1} \mathbf{a}^{\mathbf{c}}$ & 23 & 74 \\
$\mathbf{2} \mathbf{a}^{\mathrm{c}}$ & 26 & 51 \\
$\mathbf{3 a}^{\mathrm{c}}$ & 29 & 27 \\
$\mathbf{4 a} \mathbf{a}^{\mathrm{c}}$ & 28 & 27 \\
$\mathbf{5 a}$ & 99 & 94 \\
$\mathbf{6 a}$ & $>99$ & 74 \\
$\mathbf{7 a}$ & 98 & 59 \\
$\mathbf{8 a}$ & 88 & 28 \\
$\mathbf{9 a}$ & 98 & 88 \\
$\mathbf{1 0 a}$ & $>99$ & 100 \\
\hline
\end{tabular}

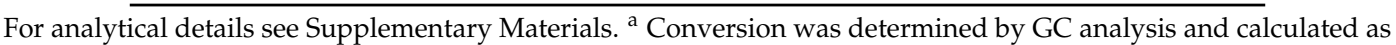
$X=\left(c_{0}-c\right) / c_{0}$, where $X$ is the conversion, $c_{0}$ is the in initial substrate concentration, and $c$ is the final substrate concentration. ${ }^{b}$ Yield was determined by GC analysis and calculated as $Y=\left(c_{p}-c_{p, 0}\right) /\left(c_{0}-c\right)$, where $Y$ is the yield, $c_{\mathrm{p}, 0}$ is the initial product concentration, $c_{\mathrm{p}}$ is the final product concentration $c_{0}$ is the initial substrate concentration, and $c$ is the final substrate concentration. ${ }^{c} 1 \mathrm{~mL}$ reaction mixture was used in a $2 \mathrm{~mL}$ glass vial and irradiated for $24 \mathrm{~h}$. Reaction conditions: $2 \mathrm{~mL}$ MilliQ water in a $4 \mathrm{~mL}$ vial, containing [SAS] $=0.75 \mathrm{mM}$ and [substrate] $=10 \mathrm{mM}$. Samples were incubated at $30^{\circ} \mathrm{C}$ and irradiated under visible light $(\lambda>400 \mathrm{~nm})$ for $9 \mathrm{~h}$.

Aromatic substrates were oxidized with good $(>80 \%)$ to excellent $(>95 \%)$ conversion. However, by increasing the length of the aliphatic side chain from 1-phenylethanol (5a) to 1-phenylbutanol (7a), the yield decreased significantly. This is likely the result of oxidative decomposition, which is enhanced by the inductive effect of the aliphatic side chain [47]. This is also supported by the results for benzyl alcohol (9a) and 3-chlorobenzyl alcohol (10a). With the presence of an electron withdrawing group on the aromatic ring, which slightly reduces the activity of the hydroxyl group, the selectivity increased. It is also worth mentioning that besides oxidation, 1,2,3,4-tetrahydro-naphtol (8a) reacted with SAS, which was indicated by the absence of the characteristic yellow color of the photocatalyst after irradiation. In contrast to the aromatic substrates, aliphatic compounds demonstrated moderate conversion $(>30 \%)$. Interestingly, C5 compounds $(\mathbf{1 a}, \mathbf{2 a})$ showed better yield than C6 compounds $(3 a, 4 a)$.

Following the photooxidation, the reductive amination step was carried out. The oxidized samples were diluted as such that the reaction mixture contained approx. $5 \mathrm{mM}$ aromatic (except $\alpha$-tetralone (8b) $1 \mathrm{mM}$ ) and 0.3-1.5 $\mathrm{mM}$ aliphatic substrate. In the reactions, the substrate scopes of five wild-type 
$\omega$-TAs were examined, one (R)-selective from Aspergillus terreus (ATwTA), and four (S)-selective

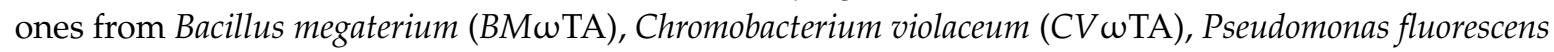

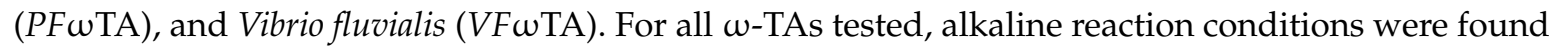
to be favorable for the reductive amination reaction (Figures S26-S30).

Amongst the prochiral compounds (Table 2), the entire range of substrates was transformed with excellent stereoselectivity $(>99 \%$ ee). Acetophenone $(\mathbf{5 b})$ was accepted by all enzymes. In the case of aromatic compounds $(5 \mathbf{b}-\mathbf{7 b})$, the conversion decreased progressively with the increasing length of the alkyl chain attached to the aromatic ring. However, VFwTA was an exception, as it similarly mediated the reductive amination of both propiophenone $(\mathbf{6 b})$ and butyrophenone $(\mathbf{7 b})$ with $35 \%$ conversion. Reductive amination of $\mathbf{8 b}$ was also feasible using BMwTA with excellent stereospecificity, which has been challenging for other systems [47,50]. Amongst the aliphatic substrates, 2-pentanone (2b) and 2-hexanal (4b) were converted to detectable levels of product only by AT $\omega T A$ and VF $\omega T A$, respectively. However, the modest performances of other enzymes are likely to be the result of the mediocre initial concentration of the substrate, as both compounds have been reported to be efficiently converted to the corresponding chiral amine [47].

Table 2. Reductive amination of ketones.

\begin{tabular}{|c|c|c|c|c|c|c|c|}
\hline & & $2 b$ & $3 b$ & $5 b$ & $6 b$ & $7 \mathbf{b}$ & $8 b$ \\
\hline \multirow{3}{*}{ ATwTA } & $c_{\text {amine }}(\mathrm{mM})^{\mathrm{a}}$ & $0.66(R)$ & n.d. & $2.8(R)$ & n.d. & n.d. & n.d. \\
\hline & Conversion $(\%)^{b}$ & 36 & n.d. & 72 & n.d. & n.d. & n.d. \\
\hline & ee $(\%)^{c}$ & $>99$ & n.d. & $>99$ & n.d. & n.d. & n.d. \\
\hline \multirow{3}{*}{$B M \omega \mathrm{TA}$} & $c_{\text {amine }}(\mathrm{mM})$ & n.d. & n.d. & $4.93(S)$ & $10.75(S)$ & n.c & $0.42(S)$ \\
\hline & Conversion $(\%)$ & n.d. & n.d. & 95 & 89 & n.d. & 20 \\
\hline & ee $(\%)$ & n.d. & n.d. & $>99$ & $>99 \%$ & n.d. & $>99 \%$ \\
\hline \multirow{3}{*}{$C V \omega \mathrm{TA}$} & $c_{\text {amine }}(\mathrm{mM})$ & n.d. & n.d. & $1.29(S)$ & n.d. & n.d. & n.d. \\
\hline & Conversion (\%) & n.d. & n.d. & 34 & n.d. & n.d. & n.d. \\
\hline & ee $(\%)$ & n.d. & n.d. & $>99$ & n.d. & n.d. & n.d. \\
\hline \multirow{3}{*}{ PFWTA } & $c_{\text {amine }}(\mathrm{mM})$ & n.d. & n.d. & $1.95(S)$ & 2.40 & n.d. & n.d. \\
\hline & Conversion (\%) & n.d. & n.d. & 43 & 35 & n.d. & n.d. \\
\hline & ee $(\%)$ & n.d. & n.d. & $>99$ & $>99$ & n.d. & n.d. \\
\hline \multirow{3}{*}{$V F \omega T A$} & $\mathrm{c}_{\text {amine }}(\mathrm{mM})$ & n.d. & $2.25(S)$ & $3.73(S)$ & 2.44 & $1.20(S)$ & n.d. \\
\hline & Conversion (\%) & n.d. & 100 & 72 & 35 & 35 & n.d. \\
\hline & ee $(\%)$ & n.d. & $>99$ & $>99$ & $>99 \%$ & $>99$ & n.d. \\
\hline
\end{tabular}

\footnotetext{
For analytical details, see Supplementary Materials. ${ }^{a}$ Amine concentration was determined by GC analysis ${ }^{b}$ Conversion was determined by GC analysis and calculated as indicated in Table 1. ${ }^{c}$ Enantiomeric excess was determined by GC analysis on a chiral stationary phase (see Supplementary Materials). ${ }^{\mathrm{d}}$ n.d.: Not determined due to low concentration. Reaction conditions: $0.5 \mathrm{~mL}$ reaction mixture in a $2 \mathrm{~mL}$ glass vial containing [NaPi] $50 \mathrm{mM}$, [crude cell extract overexpressed with $\omega$-TA enzyme] $=10 \mathrm{mg} / \mathrm{mL},[\mathrm{IPA}]=1 \mathrm{M},[\mathrm{PLP}]=1 \mathrm{mM}$, and [aromatic ketone] $\approx 5 \mathrm{mM}$ or [aliphatic ketone] $\approx 0.5 \mathrm{mM}$.
}

In the case of aldehydes, excellent conversions were achieved (Table 3). Besides VF $\omega$ TA, all the enzymes completely converted hexanal (3b) to hexylamine (3c). However, it is also important to mention that similar to the other aliphatic compounds, the initial substrate concentration was low. Both benzaldehyde (9b) and 3-chlorobenzaldehyde (10b) were fully converted to the corresponding amine.

Table 3. Reductive amination of aldehydes.

\begin{tabular}{|c|c|c|c|c|}
\hline & & $4 b$ & $9 b$ & $10 b$ \\
\hline \multirow{2}{*}{ AT $\omega \mathrm{TA}$} & $\mathrm{c}_{\text {amine }}(\mathrm{mM})^{\mathrm{a}}$ & 2.21 & 6.03 & 8.20 \\
\hline & Conversion $(\%)^{b}$ & 100 & 100 & 95 \\
\hline \multirow{2}{*}{ 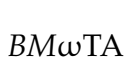 } & $c_{\text {amine }}(\mathrm{mM})$ & 2.21 & 6.86 & 11.97 \\
\hline & Conversion (\%) & 100 & 100 & 98 \\
\hline
\end{tabular}


Table 3. Cont.

\begin{tabular}{|c|c|c|c|c|}
\hline & & $4 b$ & $9 b$ & $10 \mathrm{~b}$ \\
\hline \multirow[b]{2}{*}{$C V \omega \mathrm{TA}$} & $c_{\text {amine }}(\mathrm{mM})$ & 2.21 & 7.00 & 12.82 \\
\hline & Conversion $(\%)$ & 100 & 100 & 91 \\
\hline \multirow{2}{*}{ PFwTA } & $\mathrm{c}_{\text {amine }}(\mathrm{mM})$ & 2.21 & 6.84 & 11.79 \\
\hline & Conversion $(\%)$ & 100 & 100.00 & 91 \\
\hline \multirow{2}{*}{$V F \omega \mathrm{TA}$} & $\mathrm{c}_{\text {amine }}(\mathrm{mM})$ & n.d. ${ }^{c}$ & 7.19 & 11.83 \\
\hline & Conversion $(\%)$ & n.d. & 100.00 & 98 \\
\hline
\end{tabular}

For analytical details, see Supplementary Materials. ${ }^{a}$ Amine concentration was determined by GC analysis ${ }^{b}$ Conversion was determined by GC analysis and calculated as indicated in Table $1 .{ }^{c}$ n.d.: Not determined due to low concentration. Reaction conditions: $0.5 \mathrm{~mL}$ reaction mixture in a $2 \mathrm{~mL}$ glass vial containing $[\mathrm{NaPi}]=50 \mathrm{mM}$, [crude cell extract overexpressed with $\omega$-TA enzyme] $=10 \mathrm{mg} / \mathrm{mL},[\mathrm{IPA}]=1 \mathrm{M},[\mathrm{PLP}]=1 \mathrm{mM}$, and [aromatic ketone] $\approx 5 \mathrm{mM}$ or [aliphatic ketone] $\approx 0.5 \mathrm{mM}$.

\section{Materials and Methods}

All chemicals were purchased Sigma-Aldrich (Zwijndrecht, The Netherlands), Fluka (Buchs, Switzerland), Acros (Geel, Belgium) or Alfa-Aesar (Karlsruhe, Germany) with the highest purity available and used without further treatment. The $\omega$-transaminases were prepared via recombinant expression in Escherichia coli as described in detail in the Supplementary Materials.

\subsection{Reaction Conditions for the One-Pot One-Step Cascade}

In a $2 \mathrm{~mL}$ glass vial, $1 \mathrm{~mL} \mathrm{pH} 9$ reaction mixture was prepared, containing $100 \mathrm{mM}$ sodium phosphate (NaPi), approx. $11 \mathrm{mM}$ 1-phenylethanol (or one of the other alcohols investigated here), $1 \mathrm{mM}$ pyridoxal-5-phosphate (PLP), $0.75 \mathrm{mM}$ sodium anthraquinone-2-sulfonate (SAS), $1 \mathrm{M}$ isopropylamine (IPA), and $10 \mathrm{mg}$ lyophilized crude cell extract overexpressed with $(R)$ - or (S)-selective $\omega$-transaminase ( $\omega$-TA). Samples were irradiated under visible light (Osram Halolux CERAM 205W light bulb; $\lambda>400 \mathrm{~nm})$ at $30^{\circ} \mathrm{C}$. The reaction mixture was stirred gently with a magnetic stirrer. At intervals, aliquots were taken, extracted with ethyl acetate, derivatized, and analyzed by gas chromatography (see Supplementary Materials).

\subsection{Reaction Conditions for the One-Pot Two-Step Cascade}

If not stated otherwise, in a $4 \mathrm{~mL}$ vial, $2 \mathrm{~mL}$ MilliQ water containing approx. $10 \mathrm{mM}$ substrate and $0.75 \mathrm{mM}$ SAS were irradiated with visible light (Osram Halolux CERAM 205W light bulb; $\lambda>400 \mathrm{~nm}$ ) at $30^{\circ} \mathrm{C}$. The reaction mixture was gently stirred with a magnetic stirrer. At intervals, aliquots were taken, extracted with ethyl acetate, and analyzed by gas chromatography without derivatization (see Supplementary Materials). After the irradiation, $250 \mu \mathrm{L}$ reaction mixture was diluted to $500 \mu \mathrm{L}$ by using $\mathrm{NaPi}(100 \mathrm{mM})$ as such that the final samples contained NaPI (50 mM), IPA (1M), PLP (1 mM), and $10 \mathrm{mg} / \mathrm{mL}$ lyophilized whole cells overexpressed with $(R)$ - or $(S)$-selective $\omega$-TA. The $\mathrm{pH}$ of the system was adjusted to $\mathrm{pH}$ 9. Samples were incubated on a shaking plate at $30^{\circ} \mathrm{C}$ with $600 \mathrm{rpm}$ shaking speed. At intervals, aliquots were taken, extracted with ethyl acetate, derivatized, and analyzed by gas chromatography (see Supplementary Materials).

\subsection{Derivatization of GC Samples}

Samples $(75 \mu \mathrm{L})$ were extracted with ethyl acetate $(150 \mu \mathrm{L})$ dried $\left(\mathrm{MgSO}_{4}, 5 \mathrm{mg}\right)$ and reacted with acetic anhydride $(10 \mu \mathrm{L})$ in the presence of 4 -( $N, N$-dimethylamino)pyridine $(5 \mathrm{mg})$ at $45^{\circ} \mathrm{C}$ for $45 \mathrm{~min}$. The reaction was quenched with water $(75 \mu \mathrm{L})$ and the samples were dried $\left(\mathrm{MgSO}_{4}, 5 \mathrm{mg}\right)$ again.

\section{Conclusions}

In summary, a reaction sequence of consecutive photooxidation and reductive amination of various alcohols in one pot is reported. The tandem reaction with sodium anthraquinone-2-sulfonate 
(SAS) as a photocatalyst was also feasible in a one-pot one-step approach; however, the yield was significantly inferior to the one-pot two-step case. The system was tested on a plethora of aromatic and aliphatic substrates. Even though all of the compounds were converted, the photooxidation of aromatic substrates proceeded much faster and with a higher yield. In the second step of the cascade

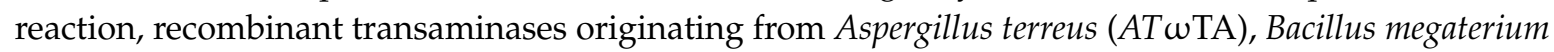

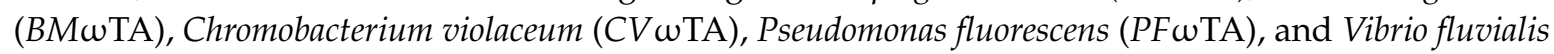
(VF $\omega \mathrm{TA}$ ) were used for the reductive amination. All of the non-chiral substrates were converted with high conversion and the prochiral substrates with excellent enantiomeric excess.

One issue en route to the preparative application is the inactivation of the biocatalysts by the photoexcited photocatalysts. This may be overcome by special separation of the photocatalytic oxidation step from the reductive amination step. For this, for example, immobilized catalysts in a flow chemistry setup may be a doable approach.

Supplementary Materials: The following are available online at http:/ /www.mdpi.com/2073-4344/9/4/305/s1. Figure S1: SDS-Page for the expression of the wTAs; Figure S2: FT-IR spectrum of SAS; Figure S3: FT-IR spectrum of g-C3N4; Figure S4: XRD spectrum of g-C3N4; Figure S5: FT-IR spectrum of g-C3N4; Figure S6: XRD spectrum of g-C3N4-VO; Figure S7: Effect of evaporation on the acetophenone concentration during the photo-oxidation of 1-phenylethanol; Figure S8: Control reaction of the photooxidation; Figure S9: Effect of the circumstances of the photooxidation on the efficiency of the reductive amination; Figure S10: Control reaction of the reductive amination; Figure S11: 1H NMR spectrum of 1-phenylethyl amine; Figure S12: 1H NMR spectrum of oxidation of 1-phenylethylamine; Figure S13: 1H NMR spectrum of oxidation of isopropylamine; Figure S14: Effect of light intensity on the photocatalytic activity of SAS; Figure S15: Effect of light composition on the photocatalytic activity of SAS; Figure S16: Effect of the reaction atmosphere on the photocatalytic activity of SAS; Figure S17: Effect of the amount of photocatalyst on the photocatalytic activity of SAS; Figure S18: Effect of pH on the photocatalytic activity of SAS; Figure S19: Effect of light composition on the photocatalytic activity of g-C3N4; Figure S20: Effect of the reaction atmosphere on the photocatalytic activity of g-C3N4; Figure S21: Effect of the photocatalyst amount on the photocatalytic activity of g-C3N4; Figure S22: Effect of the $\mathrm{pH}$ on the photocatalytic activity of g-C3N4; Figure S23: Effect of the enzyme concentration on the yield of the reductive amination; Figure S24: Effect of the amine donor concentration on the conversion of the reductive amination; Figure S25: Effect of the cofactor concentration on the yield of the reductive amination; Figure S26: $\mathrm{pH}$ dependency of AT $\omega$-TA; Figure S27: $\mathrm{pH}$ dependency of BM $\omega$ TA; Figure S28: $\mathrm{pH}$ dependency of VF $\omega$ TA; Figure S29: $\mathrm{pH}$ dependency of PF $\omega T A$; Figure S30: $\mathrm{pH}$ dependency of CV $\omega \mathrm{TA}$; Figure S31: Representative GC chromatogram of SAS catalyzed photooxidation of 1-pentanol; Figure S32: Representative GC chromatogram of SAS catalyzed photooxidation of 2-pentanol; Figure S33: Representative GC chromatogram of SAS catalyzed photooxidation of 1-hexanol; Figure S34: Representative GC chromatogram of SAS catalyzed photooxidation of 2-hexanol; Figure S35: Representative GC chromatogram of SAS catalyzed photooxidation of 1-phenylethanol; Figure S36: Representative GC chromatogram of SAS catalyzed photooxidation of 1-phenylpropanol; Figure S37: Representative GC chromatogram of SAS catalyzed photooxidation of 1-phenylbutanol; Figure S38: Representative GC chromatogram of SAS catalyzed photooxidation of 1,2,3,4-tetrahydro-1-naphtol; Figure S39: Representative GC chromatogram of SAS catalyzed photooxidation of benzyl alcohol; Figure S40: Representative GC chromatogram of SAS catalyzed photooxidation of 3-chlorobenzyl alcohol; Figure S41: Representative GC chromatogram of derivatized n-pentylamine; Figure S42: Representative GC chromatogram of derivatized 2-aminopentane; Figure S43: Representative GC chromatogram of derivatized 1-hexanol, hexanal and 1-hexylamine mixture; Figure S44: Representative GC chromatogram of derivatized 2-aminohexane; Figure S45: Representative GC chromatogram of derivatized 1-phenylethanol, acetophenone and 1-phenylethyl amine; Figure S46: Representative GC chromatogram of derivatized 1-phenylpropanol, propiophenone (R) and (S) 1-phenylpropyl amine; Figure S47: Representative GC chromatogram of derivatized 1,2,3,4-tetrahydro-1-naphthol, $\alpha$-tetralone, (R) and (S) 1,2,3,4-tetrahydro-1-naphthylamine; Figure S48: Representative GC chromatogram of derivatized benzyl alcohol, benzaldehyde, benzyl amine; Figure S49: Representative GC chromatogram of derivatized 3-chlorobenzyl alcohol, 3-chlorobenzaldehyde, 3-chlorobenzyl amine, Table S1: Used GC systems; Table S2: Details of GC analysis of the alcohol oxidation; Table S3: Details of GC analysis of the reductive amination.

Author Contributions: Conceptualization, F.H.; methodology, J.G., W.Z., T.K., F.G.M., and I.W.C.E.A; validation, J.G., W.Z., T.K., F.G.M., and I.W.C.E.A; formal analysis, J.G., W.Z., and F.H., writing-original draft preparation, J.G. and W.Z., writing - review and editing, W.Z. and F.H.

Funding: This research was funded by the European Research Council (ERC Consolidator Grant No. 648026).

Acknowledgments: We thank Remco van Oosten for help with GC method development.

Conflicts of Interest: The authors declare no conflict of interest. 


\section{References}

1. Nugent, T.C.; El-Shazly, M. Chiral amine synthesis-Recent developments and trends for enamide reduction, reductive amination, and imine reduction. Adv. Synth. Catal. 2010, 352, 753-819. [CrossRef]

2. Welsch, M.E.; Snyder, S.A.; Stockwell, B.R. Privileged scaffolds for library design and drug discovery. Curr. Opin. Chem. Biol. 2010, 14, 347-361. [CrossRef]

3. Newman, D.J.; Cragg, G.M. Natural products as sources of new drugs over the 30 years from 1981 to 2010. J. Nat. Prod. 2012, 75, 311-335. [CrossRef] [PubMed]

4. Green, A.P.; Turner, N.J.; O’Reilly, E. Chiral amine synthesis using omega-transaminases: An amine donor that displaces equilibria and enables high-throughput screening. Angew. Chem. Int. Ed. 2014, 53, 10714-10717. [CrossRef]

5. Bähn, S.; Imm, S.; Neubert, L.; Zhang, M.; Neumann, H.; Beller, M. The catalytic amination of alcohols. ChemCatChem 2011, 3, 1853-1864. [CrossRef]

6. Imm, S.; Bähn, S.; Zhang, M.; Neubert, L.; Neumann, H.; Klasovsky, F.; Pfeffer, J.; Haas, T.; Beller, M. Improved ruthenium-catalyzed amination of alcohols with ammonia: Synthesis of diamines and amino esters. Angew. Chem. Int. Ed. 2011, 50, 7599-7603. [CrossRef] [PubMed]

7. Mutti, F.G.; Knaus, T.; Scrutton, N.S.; Breuer, M.; Turner, N.J. Conversion of alcohols to enantiopure amines through dual-enzyme hydrogen-borrowing cascades. Science 2015, 349, 1525-1529. [CrossRef] [PubMed]

8. Lawrence, S.A. Amines: Synthesis, Properties and Applications; Cambridge University Press: Cambridge, UK, 2004.

9. Fabiano, E.; Golding, B.T.; Sadeghi, M.M. A simple conversion of alcohols into amines. Synthesis 1987, 1987, 190-192. [CrossRef]

10. Xu, C.; Zhang, C.H.; Li, H.; Zhao, X.Y.; Song, L.; Li, X.B. An overview of selective oxidation of alcohols: Catalysts, oxidants and reaction mechanisms. Catal. Surv. Asia 2016, 20, 13-22. [CrossRef]

11. Mallat, T.; Baiker, A. Oxidation of alcohols with molecular oxygen on solid catalysts. Chem. Rev. 2004, 104, 3037-3058. [CrossRef]

12. Schultz, M.J.; Sigman, M.S. Recent advances in homogeneous transition metal-catalyzed aerobic alcohol oxidations. Tetrahedron 2006, 62, 8227-8241. [CrossRef]

13. Arends, I.W.C.E.; Sheldon, R.A. Modern oxidation of alcohols using environmentally benign oxidants. In Modern Oxidation Method; Bäckvall, J.-E., Ed.; Wiley-VCH: Weinheim, Germany, 2010; Volume 2, pp. 147-185.

14. Davis, S.E.; Ide, M.S.; Davis, R.J. Selective oxidation of alcohols and aldehydes over supported metal nanoparticles. Green Chem. 2013, 15, 17-45. [CrossRef]

15. Irie, H.; Miura, S.; Kamiya, K.; Hashimoto, K. Efficient visible light-sensitive photocatalysts: Grafting Cu(II) ions onto $\mathrm{TiO}(2)$ and $\mathrm{WO}(3)$ photocatalysts. Chem. Phys. Lett. 2008, 457, 202-205. [CrossRef]

16. Shishido, T.; Miyatake, T.; Teramura, K.; Hitomi, Y.; Yamashita, H.; Tanaka, T. Mechanism of photooxidation of alcohol over nb2o5. J. Phys. Chem. C 2009, 113, 18713-18718. [CrossRef]

17. Furukawa, S.; Shishido, T.; Teramura, K.; Tanaka, T. Photocatalytic oxidation of alcohols over $\mathrm{TiO}_{2}$ covered with $\mathrm{Nb}_{2} \mathrm{O}_{5}$. ACS Catal. 2012, 2, 175-179. [CrossRef]

18. Chen, J.; Cen, J.; Xu, X.L.; Li, X.N. The application of heterogeneous visible light photocatalysts in organic synthesis. Catal. Sci. Technol. 2016, 6, 349-362. [CrossRef]

19. Su, F.Z.; Mathew, S.C.; Lipner, G.; Fu, X.Z.; Antonietti, M.; Blechert, S.; Wang, X.C. Mpg-C ${ }_{3} \mathrm{~N}_{4}$-catalyzed selective oxidation of alcohols using O-2 and visible light. J. Am. Chem. Soc. 2010, 132, 16299-16301. [CrossRef]

20. Zhang, L.G.; Liu, D.; Guan, J.; Chen, X.F.; Guo, X.C.; Zhao, F.H.; Hou, T.G.; Mu, X.D. Metal-free g-C ${ }_{3} \mathrm{~N}_{4}$ photocatalyst by sulfuric acid activation for selective aerobic oxidation of benzyl alcohol under visible light. Mater. Res. Bull. 2014, 59, 84-92. [CrossRef]

21. Verma, S.; Baig, R.B.N.; Nadagouda, M.N.; Varma, R.S. Selective oxidation of alcohols using photoactive vo@g- $\mathrm{C}_{3} \mathrm{~N}_{4}$. ACS Sustain. Chem. Eng. 2016, 4, 1094-1098. [CrossRef]

22. Zavahir, S.; Xiao, Q.; Sarina, S.; Zhao, J.; Bottle, S.; Wellard, M.; Jia, J.F.; Jing, L.Q.; Huang, Y.M.; Blinco, J.P.; et al. Selective oxidation of aliphatic alcohols using molecular oxygen at ambient temperature: Mixed-valence vanadium oxide photocatalysts. ACS Catal. 2016, 6, 3580-3588. [CrossRef] 
23. Clark, K.P.; Stonehil, H.I. Photochemistry and radiation-chemistry of anthraquinone-2-sodium-sulphonate in aqueous-solution Part 1. Photochemical kinetics in aerobic solution. J. Chem. Soc. Faraday Trans. I 1972, 68, 577-590. [CrossRef]

24. Clark, K.P.; Stonehil, H.I. Photochemistry and radiation-chemistry of 9,10-anthraquinone-2-sodium sulfonate in aqueous-solution Part 2. Photochemical products. J. Chem. Soc. Faraday Trans. I 1972, 68, 1676-1686. [CrossRef]

25. Wells, C.F. Hydrogen transfer to quinones Part 2. Reactivities of alcohols, ethers and ketones. Trans. Faraday Soc. 1961, 57, 1719-1731. [CrossRef]

26. Wells, C.F. Hydrogen transfer to quinones Part 1. Kinetics of deactivation of photo-excited quinone. Trans. Faraday Soc. 1961, 57, 1703-1718. [CrossRef]

27. Zhang, W.; Gacs, J.; Arends, I.W.C.E.; Hollmann, F. Selective photooxidation reactions using water soluble anthraquinone photocatalysts. ChemCatChem 2017, 9, 3821-3826. [CrossRef]

28. Zhang, W.; Fernandez Fueyo, E.; Hollmann, F.; Leemans Martin, L.; Pesic, M.; Wardenga, R.; Höhne, M.; Schmidt, S. Combining photo-organo redox- and enzyme catalysis facilitates asymmetric C-H bond functionalization. Eur. J. Org. Chem. 2019, 10, 80-84. [CrossRef]

29. Fuchs, C.S.; Farnberger, J.E.; Steinkellner, G.; Sattler, J.H.; Pickl, M.; Simon, R.C.; Zepeck, F.; Gruber, K.; Kroutil, W. Asymmetric amination of $\alpha$-chiral aliphatic aldehydes via dynamic kinetic resolution to access stereocomplementary brivaracetam and pregabalin precursors. Adv. Synth. Catal. 2018, 360, 768-778. [CrossRef]

30. Hohne, M.; Bornscheuer, U.T. Biocatalytic routes to optically active amines. ChemCatChem 2009, 1, 42-51. [CrossRef]

31. Ward, J.; Wohlgemuth, R. High-yield biocatalytic amination reactions in organic synthesis. Curr. Org. Chem. 2010, 14, 1914-1927. [CrossRef]

32. Slabu, I.; Galman, J.L.; Lloyd, R.C.; Turner, N.J. Discovery, engineering, and synthetic application of transaminase biocatalysts. ACS Catal. 2017, 7, 8263-8284. [CrossRef]

33. Fuchs, M.; Farnberger, J.E.; Kroutil, W. The industrial age of biocatalytic transamination. Eur. J. Org. Chem. 2015, 2015, 6965-6982. [CrossRef]

34. Kelly, S.A.; Pohle, S.; Wharry, S.; Mix, S.; Allen, C.C.R.; Moody, T.S.; Gilmore, B.F. Application of omega-transaminases in the pharmaceutical industry. Chem. Rev. 2018, 118, 349-367. [CrossRef] [PubMed]

35. Savile, C.K.; Janey, J.M.; Mundorff, E.C.; Moore, J.C.; Tam, S.; Jarvis, W.R.; Colbeck, J.C.; Krebber, A.; Fleitz, F.J.; Brands, J.; et al. Biocatalytic asymmetric synthesis of chiral amines from ketones applied to sitagliptin manufacture. Science 2010, 329, 305-309. [CrossRef] [PubMed]

36. Palacio, C.M.; Crismaru, C.G.; Bartsch, S.; Navickas, V.; Ditrich, K.; Breuer, M.; Abu, R.; Woodley, J.M.; Baldenius, K.; Wu, B.; et al. Enzymatic network for production of ether amines from alcohols. Biotechnol. Bioeng. 2016, 113, 1853-1861. [CrossRef] [PubMed]

37. Mathew, S.; Yun, H. $\Omega$-transaminases for the production of optically pure amines and unnatural amino acids. ACS Catal. 2012, 2, 993-1001. [CrossRef]

38. Sattler, J.H.; Fuchs, M.; Mutti, F.G.; Grischek, B.; Engel, P.; Pfeffer, J.; Woodley, J.M.; Kroutil, W. Introducing an in situ capping strategy in systems biocatalysis to access 6-aminohexanoic acid. Angew. Chem. Int. Ed. 2014, 53, 14153-14157. [CrossRef]

39. Wang, B.; Land, H.; Berglund, P. An efficient single-enzymatic cascade for asymmetric synthesis of chiral amines catalyzed by [small omega]-transaminase. Chem. Comm. 2013, 49, 161-163. [CrossRef] [PubMed]

40. Martínez-Montero, L.; Gotor, V.; Gotor-Fernández, V.; Lavandera, I. But-2-ene-1,4-diamine and but-2-ene-1,4-diol as donors for thermodynamically favored transaminase- and alcohol dehydrogenase-catalyzed processes. Adv. Synth. Catal. 2016, 358, 1618-1624. [CrossRef]

41. Gomm, A.; Lewis, W.; Green, A.P.; O'Reilly, E. A new generation of smart amine donors for transaminase-mediated biotransformations. Chem. Eur. J. 2016, 22, 12692-12695. [CrossRef]

42. Tufvesson, P.; Jensen, J.S.; Kroutil, W.; Woodley, J.M. Experimental determination of thermodynamic equilibrium in biocatalytic transamination. Biotechnol. Bioeng. 2012, 109, 2159-2162. [CrossRef] [PubMed]

43. Martinez-Montero, L.; Gotor, V.; Gotor-Fernandez, V.; Lavandera, I. Stereoselective amination of racemic sec-alcohols through sequential application of laccases and transaminases. Green Chem. 2017, 19, 474-480. [CrossRef] 
44. Sattler, J.H.; Fuchs, M.; Tauber, K.; Mutti, F.G.; Faber, K.; Pfeffer, J.; Haas, T.; Kroutil, W. Redox self-sufficient biocatalyst network for the amination of primary alcohols. Angew. Chem. Int. Ed. 2012, 51, 9156-9159. [CrossRef]

45. Schrittwieser, J.H.; Sattler, J.; Resch, V.; Mutti, F.G.; Kroutil, W. Recent biocatalytic oxidation-reduction cascades. Curr. Opin. Chem. Biol. 2011, 15, 249-256. [CrossRef]

46. Sheldon, R.A. The E factor 25 years on: The rise of green chemistry and sustainability. Green Chem. 2017, 19, 18-43. [CrossRef]

47. Mutti, F.G.; Fuchs, C.S.; Pressnitz, D.; Sattler, J.H.; Kroutil, W. Stereoselectivity of four (R)-selective transaminases for the asymmetric amination of ketones. Adv. Synth. Catal. 2011, 353, 3227-3233. [CrossRef]

48. Mutti, F.G.; Kroutil, W. Asymmetric bio-amination of ketones in organic solvents. Adv. Synth. Catal. 2012, 354, 3409-3413. [CrossRef]

49. Cassimjee, K.E.; Humble, M.S.; Miceli, V.; Colomina, C.G.; Berglund, P. Active site quantification of an $\omega$-transaminase by performing a half transamination reaction. ACS Catal. 2011, 1, 1051-1055. [CrossRef]

50. Fesko, K.; Steiner, K.; Breinbauer, R.; Schwab, H.; Schurmann, M.; Strohmeier, G.A. Investigation of one-enzyme systems in the omega-transaminase-catalyzed synthesis of chiral amines. J. Mol. Catal. B Enzym. 2013, 96, 103-110. [CrossRef]

(C) 2019 by the authors. Licensee MDPI, Basel, Switzerland. This article is an open access article distributed under the terms and conditions of the Creative Commons Attribution (CC BY) license (http://creativecommons.org/licenses/by/4.0/). 